\title{
PENGARUH FAKTOR TEKNIS PENANGKAPAN TERHADAP JUMLAH HASIL TANGKAPAN POLE AND LINE DI PERAIRAN TELUK BONE
}

\section{THE EFFECT OF TEHNICAL FACTORS ON POLE AND LINE CATCHES IN THE BONE}

\author{
Delvi Yustina Sari ${ }^{1 *}$, Faisal Amir ${ }^{1}$, Alfa F.P Nelwan ${ }^{1}$ \\ ${ }^{1}$ Program Studi Pemanfaatan Sumberdaya Perikanan, Fakultas Ilmu Kelautan dan Perikanan, Universitas Ha- \\ sanuddin
}

Diterima: 06 Januari 2019; Disetujui: 21 Februari 2019

\begin{abstract}
ABSTRAK
Penelitian ini bertujuan untuk menentukan faktor teknis penangkapan yang berpengaruh terhadap jumlah hasil tangkapan pole and line di perairan Teluk Bone dan mendeskripsikan sebaran daerah penangkapan ikan pole and line di perairan Teluk Bone. Penelitian dilakukan pada bulan Mei 2018 sampai Agustus 2018. Pengambilan data dilakukan dengan mengikuti secara langsung operasi penangkapan ikan menggunakan kapal pole and line sebanyak 30 trip penangkapan. Analisis data hubungan antara jumlah hasil tangkapan dengan faktor teknis penangkapan (bahan bakar, jumlah umpan, lama waktu pemancingan, dan jarak penangkapan) yaitu menggunakan analisis uji statistik non-parametrik korelasi Spearman. Faktor teknis penangkapan merupakan serangkaian aktivitas penangkapan untuk memperoleh hasil tangkapan optimal serta mempermudah kegiatan operasi penangkapan ikan. Hasil penelitian menunjukkan faktor teknis penangkapan yang berpengaruh terhadap jumlah hasil tangkapan pole and line di perairan Teluk Bone yang paling berpengaruh adalah lama waktu efektif pemancingan. Sebaran daerah penangkapan ikan pole and line di perairan Teluk Bone terlihat tersebar di bagian tengah perairan Teluk Bone.
\end{abstract}

Kata Kunci: Pole and line, Faktor teknis, Teluk Bone, Ikan Cakalang

\begin{abstract}
This study aimed to determine the fishing technical factors that influence the number of pole and line catches and described the distribution of pole and line fishing grounds in the Bone Gulf. The study was conducted in May until August 2018. Data were collected by directly participating in fishing operations using pole and liner for 30 fishing trips. Analysis of data on the relationship between the number of catches and fishing technical factors (fuel, number of feeds, length of fishing time, and fishing distance), namely using the Spearman correlation non-parametric statistical test analysis. The fishing technical factor were the series of fishing activities to obtain optimal catches and facilitate fishing operations. The results of the study showed that the technical factors the most influential of fishing that influence the amount of catch pole and liner in the Bone Gulf were the effective length of fishing. Some pole and liner fishing grounds in the waters Bone Gulf were seen scattered in the middle of the Bone Gulf.
\end{abstract}

Keywords: Pole and line, Technical Factors, Bone Gulf, Skipjack tuna

\begin{tabular}{ll}
\hline Contact person & : Delvi Yustina Sari \\
E-Mail & $:$ delviyustina14@gmail.com
\end{tabular}




\section{PENDAHULUAN}

Alat tangkap pole and line biasa juga di sebut "Huhate". Huhate termasuk klasifikasi pancing yang memiliki desain yang sederhana terdiri dari joran, tali, dan mata pancing. Alat tangkap pole and line juga dalam pengoperasiannya sangat di pengaruhi oleh keterampilan dan pengalaman seorang pemancing. Selain itu untuk mencapai hasil yang optimal harus di dukung tersedianya umpan hidup, keadaan air yang memungkinkan untuk melakukan operasi (kondisi cuaca). Dan ada tidaknya gerombolan ikan serta tingkat kepadatannya pada suatu fishing ground (Syahrir, 2012).

Pole qand line biasanya dipakai untuk menangkap cakalang, sehingga alat ini sering disebut "pancing cakalang". Pole and line dioperasikan sepanjang siang hari pada saat terdapat gerombolan ikan di sekitar kapal. Alat tangkap ini bersifat aktif, kapal akan mengejar gerombolan ikan, setelah gerombolan ikan berada di sekitar kapal lalu diadakan pemancingan.

Faktor teknis penangkapan merupakan serangkaian aktivitas penangkapan untuk memperoleh hasil tangkapan optimal serta mempermudah kegiatan operasi penangkapan ikan. Berdasarkan jumlah hasil tangkapan yang di hasilkan suatu alat tangkap pole and line, terdapat empat faktor teknis penangkapan yang sangat berpengaruh untuk meningkatkan efisiensi dalam penangkapan yakni jumlah bahan bakar, jumlah umpan, jarak penangkapan, dan lama waktu pemancingan. Seberapa besar pengaruh ke empat faktor tersebut dalam menentukan efisiensi penangkapan yang di lakukan. Maka penelitian mengenai "Pengaruh faktor teknis penangkapan terhadap jumlah hasil tangkapan di TPI Murante" perlu di lakukan agar hasil penelitian dapat menjadi informasi penting bagi nelayan untuk mengoptimalkan hasil tangkap.

\section{METODE PENELITIAN}

\section{Waktu dan Tempat}

Penelitian ini dilaksanakan pada lokasi fishing ground Perairan Teluk Bone dengan fishing base di Desa Murante, Kecamatan Suli, Kabupaten Luwu, dengan fising base di TPI Murante, dari bulan mei 2018 sampai Agustus 2018.

\section{Metode Pengumpulan Data}

Metode yang digunakan untuk kegiatan penelitian ini adalah metode studi kasus pada satu unit pole and line. Penentuan satu unit kapal pole and line di lakukan secara sengaja karena pole and line di kabupaten Luwu memiliki ukuran kapal relatif sama. Data yang di kumpulkan adalah data primer dan sekunder.

1. Pengumpulan Data Primer 
Data primer di peroleh melalui observasi langsung dengan mengikuti operasi penangkapan pada satu unit pole and line di Kabupaten Luwu sebanyak 30 trip penangkapan. Adapun prosedur pengumpulan data secara primer meliputi:

a. Data jumlah bahan bakar yang di gunakan pada unit penangkapan pole and line selama satu kali beroperasi di hitung dengan satuan liter.

b. Data jumlah umpan ikan hidup yang di gunakan selama pemancingan setiap satu kali operasi penangkapan yang di hitung dengan satuan ember.

c. Penentuan jarak fishing base ke fishing ground yakni mengkonversi menggunakan aplikasi ArcGis. Jarak yang di tempu dari fishing base menuju ke fishing ground pada unit penangkapan pole and line di perairan Teluk Bone dengan satuan km.

d. Menentukan berapa lama waktu pemancingan di hitung pada saat boy-boy mulai menurunkan umpan hidup hingga selesainya waktu pemancingan di tandai dengan berhentinya kegiatan pemancingan, di hitung mengunakan stopwatch. Waktu pemancingan di kategorikan menjadi dua yaitu pagi hari sampai siang hari dan siang hari sampai sore hari. e. Melakukan wawancara dengan nelayan untuk melengkapi data yang diinginkan.

\section{Pengumpulan Data Sekunder}

Data sekunder diperoleh dari studi literatur sebagai penunjang penelitian untuk menunjukkan keabsahan suatu penelitian, dan mengetahui jenis ikan yang tertangkap dengan mencocokkan beberapa literatur digunakan antara lain (Allen, 1999), dan website http//:www.fishbase.org.

\section{Analisis Data}

\section{Analisis Hubungan antara Pengaruh Faktor Teknis terhadap Jumlah Hasil Tangkapan}

Untuk menyatakan hubungan antara pengaruh faktor teknis terhadap jumlah hasil tangkapan, di gunakan analisi regresi linear non berganda (Cobb douglas).

Sebelum di lakukan uji Cobb douglas, terlebih dahulu di lakukan uji normalitas sebaran data sebagai syarat untuk analisis statistik parametrik. Karena data tersebut tidak terdistribusi normal maka di lakukan transformasi data dengan cara di pangkatkan, di logaritmakan, dan Ln (Lampiran 1). Setelah itu di lakukan transformasi, ternyata data tersebut masih tidak normal sehingga di lakukan analisis regresi non-parametrik Spearman.

Analisis hubungan antara jumlah hasil tangkapan dengan faktor teknis penangkapan (bahan bakar, jumlah umpan, lama waktu 
pemancingan, dan jarak penangkapan) yaitu menggunakan analisis uji statistik nonparametrik korelasi Spearman dengan persamaan sebagai berikut :

$$
\rho=\frac{1-6 \sum \mathrm{D}}{\mathrm{n}\left(\mathrm{n}^{2}-1\right)}
$$

\section{Dimana :}

$\rho \quad$ : Koefisien Korelasi Spearman

D : Perbedaan skor antar 2 variabel (hasil tangkapan dengan parameter faktor teknis penangkapan)

$\mathrm{N}$ : Jumlah kelompok

Menentukan Hipotesis :

$\mathrm{H}_{0}$ : ada hubungan yang signifikan antara hasil tangkapan dengan faktor teknis penangkapan

$\mathrm{H}_{1}$ : tidak ada hubungan yang signifikan antara hasil tangkapan dengan faktor teknis penangkapan

Pengambilan keputusan :

Sig.(2-tailed) $\leq \mathrm{a} / 2(\mathrm{a}=0.05) \rightarrow$ terima $\mathrm{H}_{0}$

Sig. $(2$-tailed $) \geq a / 2(a=0.05) \rightarrow$ tolak $\mathrm{H}_{1}$

\section{Analisis sebaran daerah penangkapan ikan dengan pole and line}

Untuk mengetahui sebaran daerah penangkapan ikan dengan pole and line mengunakan aplikasi ArgGIS. Titik tangkapan yang di peroleh selanjutnya di input kedalam MS Excel, kemudian di Save As ke dalam progam CSV (Comma Separated Value). Titik tangkapan di overlay ke dalam ArgGIS sehingga akan tergambarkan sebaran daerah penangkapan ikan pada tangkap pole and line di perairan Teluk Bone.

\section{HASIL DAN PEMBAHASAN}

\section{Hasil Analisis Hubungan Teknis dengan Jumlah}

antara Faktor

Hubungan antara hasil tangkapan dengan faktor teknis dapat di lihat pada Tabel 1.

\begin{tabular}{|c|c|c|c|c|}
\hline Tabel & $\begin{array}{l}1 . \quad \text { Hasil } \\
\text { antara } \\
\text { dengan }\end{array}$ & $\begin{array}{l}\text { analisis } \\
\text { jumlah } \\
\text { faktor }\end{array}$ & $\begin{array}{l}\text { korelasi } \\
\text { hasil } \\
\text { teknis }\end{array}$ & $\begin{array}{r}\text { Spearman } \\
\text { tangkapan } \\
\text { penanqkapan }\end{array}$ \\
\hline & pole and lir & & & \\
\hline
\end{tabular}

\begin{tabular}{lcc}
\hline & \multicolumn{2}{c}{ Nilai Korelasi } \\
\hline Sig. & $\begin{array}{l}\text { Jumlah Hasil } \\
\text { Tangkapan }\end{array}$ \\
\hline Jumlah Bahan Bakar & 0.343 & 0,071 \\
Jumlah Umpan & 0.018 & 0.176 \\
Lama Pemancingan & 0.000 & 0.704 \\
Jarak Penangkapan & 0.852 & -0.014 \\
\hline
\end{tabular}

Berdasarkan hasil uji statistik non parametrik Spearman menunjukkan bahwa nilai signifikansi sebesar 0.343 , karena nilai sig 0.343 > dari 0.05 maka artinya tidak ada hubungan signifikan antara variable hasil tangkapan dan bahan bakar. Nilai korelasi antara jumlah hasil tangkapan dengan jumlah bahan bakar yaitu 0,071 , nilai tersebut menandakan hubungan korelasi yang rendah antara hasil tangkapan dengan bahan bakar. Angka koefisien korelasi pada hasil analisis bernilai 
positif yaitu 0,071 sehingga hubungan kedua variabel tersebut bersifat searah.

Berdasarkan hasil uji statistik non parametrik Spearman menunjukkan bahwa nilai signifikansi sebesar 0.018 , karena nilai signifikan $0.018<$ dari 0.05 maka artinya nilai tersebut signifikan antara variable hasil tangkapan dan jumlah umpan. Namun nilai korelasi sebesar 0.176 sehingga hubungan keeratannya rendah atau cenderung tidak ada hubungan. Angka koefisien korelasi pada hasil analisis bernilai positif, yaitu 0.176 sehingga hubungan kedua variable tersebut bersifat searah.

Berdasarkan hasil uji statistik non parametrik Spearman menunjukkan bahwa nilai signifikansi sebesar 0.000 , karena nilai signifikan 0.000 < dari 0.05 maka artinya hubungan yang signifikan antara variable hasil tangkapan dan lama waktu pemancingan. Nilai korelasi menunjukkan nilai yang kuat yaitu 0.704, nilai tersebut menandakan hubungan yang kuat antara hasil tangkapan dengan lama waktu pemancingan. Angka koefisien korelasi pada hasil analisis, bernilai positif, yaitu 0.704 sehingga hubungan kedua variable tersebut bersifat searah.

Berdasarkan hasil uji statistik non parametrik Sperman menunjukkan bahwa tersebut diketahui nilai signifikansi sebesar 0.852 , karena nilai signifikan 0.852 > dari 0.05 maka artinya tidak ada hubungan yang signifikan an- tara variable hasil tangkapan dan jarak penangkapan korelasi antara hasil tangkapan dengan jarak penangkapan. Nilai korelasi menunjukkan nilai sebesar -0.014 yang nilai tersebut menandakan hubungan yang lemah antara hasil tangkapan dengan jarak penangkapan. Angka koefisien korelasi pada hasil analisis, bernilai negatif yaitu -0.014 sehingga hubungan kedua variable tersebut bersifat tidak searah. Berdasarkan hasil analisis. Hal ini menunjukkan bahwa tidak terdapat perbedaan yang signifikan antara daerah penangkapan ikan pole and line yang terletak jauh dan dekat dari pantai.

Fluktuasi hasil tangkapan berdasarkan jumlah bahan bakar dapat di lihat pada (Gambar 1).

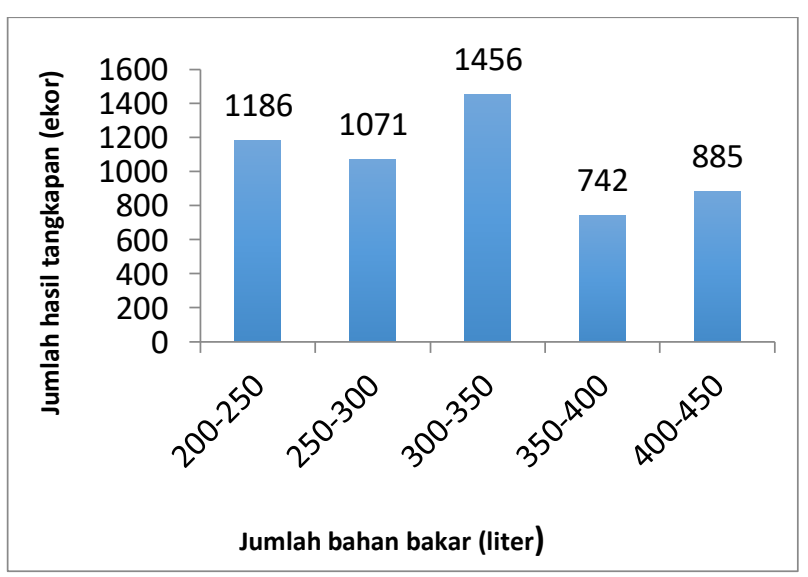

Gambar 1. Fluktuasi total hasil tangkapan berdasarkan jumlah bahan bakar

Dari gambar fluktuasi hasil tangkapan berdasarkan jumlah bahan bakar dapat diketahui bahwa hasil tangkapan tertinggi berada pada 300 - 350 liter dengan total hasil tangkapan 1456 ekor. Sedangkan terendah berada pada 
350 - 400 liter dengan total hasil tangkapan 724 ekor. Penggunaan bahan bakar yang menunjukkan angka 300 - 350 liter memiliki hasil tangkapan terbesar dikarenakan saat melaksanakan penelitian jumlah bahan bakar angka ini memiliki jumlah trip terbanyak, yang dimana dalam tiap tripnya memiliki jumlah titik pemancingan yang terbanyak, dibandingkan dengan trip lainnya, sehingga mempengaruhi jumlah hasil tangkapan itu sendiri. Fluktuasi total hasil tangkapan berdasarkan jumlah umpan dapat di lihat pada (Gambar 2).

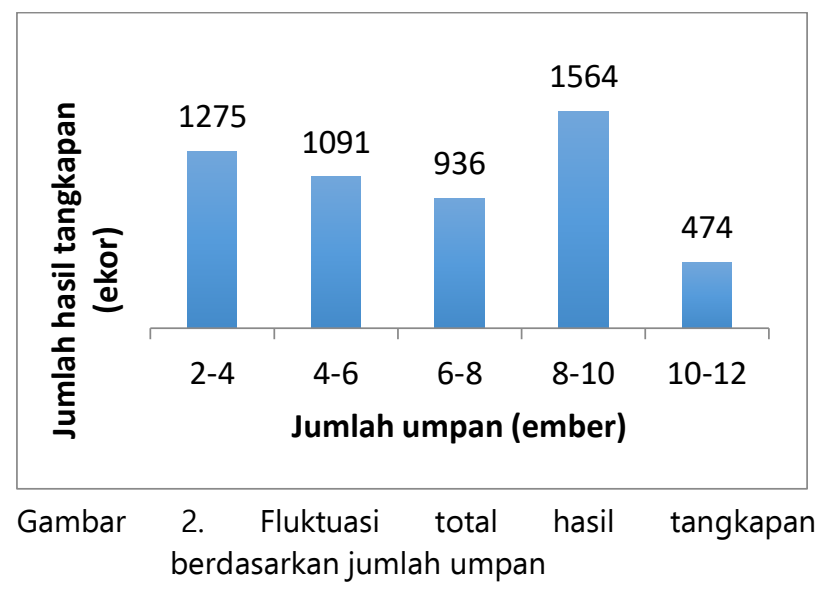

Berdasarkan gambar fluktuasi hasil tangkapan berdasarkan jumlah umpan. Hasil tangkapan tertinggi berada pada kiasaran 8-10 ember jumlah umpan dengan total hasil tangkapan 1564 ekor. Sedangkan terendah berada pada kisaran 10-12 ember jumlah umpan dengan total hasil tangkapan 474 ekor, dalam hal ini menjelaskan bahwa walaupun memiliki jumlah umpan terbesar namun belum tentu akan memiliki hasil tangkapan yang terbesar pula karena tentu akan ada faktor lain yang mempengaruhi.

Menurut (Fauzau, 2011) selain faktor perubahan kondisi oseanografi yang mempengaruhi kualitas dan kuantitas yang tertangkap, keberhasilan operasi penangkapan ikan itu sendiri masih di pengaruhi oleh faktor skill pemancing dan fishing master (boy-boy).

Data jumlah hasil tangkapan ikan (ekor) di perairan Teluk Bone kapal pole and line berdasarkan lama pemancingan di kategorikan dua bagian yaitu pada waktu pagi sampai siang hari antara pukul (06.00 - 11.59) dan siang sampai sore hari $(12.00$ - 17.00) di hitung jumlah (ekor). dapat di lihat pada Tabel 2.

$\begin{array}{lllrr}\text { Tabel } & \text { 2. Jumlah } & \text { hasil } & \text { tangkapan } & \text { ikan } \\ \text { (ekor) } & \text { kapal } & \text { pole } & \text { and } & \text { line } \\ \text { pada waktu } & \text { pagi } & \text { sampai } & \text { siang } \\ \text { hari dan } & \text { siang } & \text { hari } & \text { sampai } \\ \text { sore hari } & & & & \end{array}$

\begin{tabular}{ccc}
\hline Trip & \multicolumn{2}{c}{ Jumlah hasil tangkapan ikan (ekor) } \\
\cline { 2 - 3 } & $\begin{array}{c}\text { Pagi sampai siang } \\
\text { hari } \\
(06.00-11.59)\end{array}$ & $\begin{array}{c}\text { Siang sampai sore } \\
\text { hari } \\
(12.00-16.00)\end{array}$ \\
\hline $\mathbf{1}$ & 286 & 101 \\
\hline $\mathbf{2}$ & 95 & 197 \\
\hline $\mathbf{3}$ & 100 & 149 \\
\hline $\mathbf{4}$ & 102 & 56 \\
\hline $\mathbf{5}$ & 214 & 0 \\
\hline $\mathbf{6}$ & 78 & 184 \\
\hline $\mathbf{7}$ & 42 & 142 \\
\hline $\mathbf{8}$ & 103 & 75 \\
\hline $\mathbf{9}$ & 116 & 0 \\
\hline $\mathbf{1 0}$ & 83 & 37 \\
\hline $\mathbf{1 1}$ & 15 & 0 \\
\hline $\mathbf{1 2}$ & 48 & 62 \\
\hline $\mathbf{1 3}$ & 98 & 52 \\
\hline $\mathbf{1 4}$ & 198 & 75 \\
\hline
\end{tabular}




\begin{tabular}{ccc}
\hline $\mathbf{1 5}$ & 36 & 85 \\
\hline $\mathbf{1 6}$ & 113 & 99 \\
\hline $\mathbf{1 7}$ & 166 & 69 \\
\hline $\mathbf{1 8}$ & 102 & 49 \\
\hline $\mathbf{1 9}$ & 172 & 50 \\
\hline $\mathbf{2 0}$ & 86 & 48 \\
\hline $\mathbf{2 1}$ & 90 & 79 \\
\hline $\mathbf{2 2}$ & 89 & 30 \\
\hline $\mathbf{2 3}$ & 80 & 57 \\
\hline $\mathbf{2 4}$ & 98 & 52 \\
\hline $\mathbf{2 5}$ & 149 & 56 \\
\hline $\mathbf{2 6}$ & 59 & 139 \\
\hline $\mathbf{2 7}$ & 122 & 31 \\
\hline $\mathbf{2 8}$ & 90 & 79 \\
\hline $\mathbf{2 9}$ & 29 & 111 \\
\hline $\mathbf{3 0}$ & 137 & 58 \\
\hline Jumlah & 3196 & 2222 \\
\hline Rata-rata & 106 & 74 \\
\hline Maksimal & 286 & 101 \\
\hline Minimal & 15 & 0 \\
\hline Kisaran & $15-286$ & 101 \\
\hline & & \\
\hline
\end{tabular}

Berdasarkan Tabel 2 dapat diketahui bahwa total hasil tangkapan pole and line pada waktu pagi sampai siang hari adalah 3196 ekor, dan jumlah rata - rata hasil pada waktu pagi sampai siang hari adalah 106 ekor, sedangkan total hasil tangkapan pada waktu siang sampai sore hari adalah 2222 ekor dan jumlah ratarata hasil tangkapan pada waktu siang sampai sore hari adalah 74 ekor.

Hal ini menunjukkan jumlah hasil tangkapan pole and line antara waktu pagi sampai siang hari. Memberikan perbedaan yang nyata dengan jumlah hasil tangkapan pole and line pada waktu siang sampai sore hari, sehingga dapat disimpulkan bahwa penangkapan pada waktu pagi sampai siang hari lebih baik dibandingkan pada waktu siang sampai sore hari. Hal ini sesuai dengan pendapat (Jumardi, 2011) yang mengatakan bahwa waktu yang paling baik untuk melakukan kegiatan pemancingan pada pole and line adalah waktu pagi.

Menurut Ishal (2012) dalam skripsinya mengatakan adanya perbedaan jumlah (ekor) hasil tangkapan pole and line antara pagi sampai siang hari dan siang sampai sore hari berhubungan dengan adanya gerombolan ikan selama penelitian, dimana gerombolan ikan banyak terdapat pada waktu pagi sampai siang hari di bandingkan siang sampai sore hari.

Hal ini menunjukan bahwa penangkapan ikan menggunakan pole and line pada waktu pagi sampai siang hari berpengaruh terhadap peningkatan jumlah (ekor) hasil tangkapan. Seperti dapat di lhat pada grafik perbandingan jumlah hasil tangkapan (ekor) pole and line berdasarkan waktu yang berbeda di bawah ini (Gambar 3). 


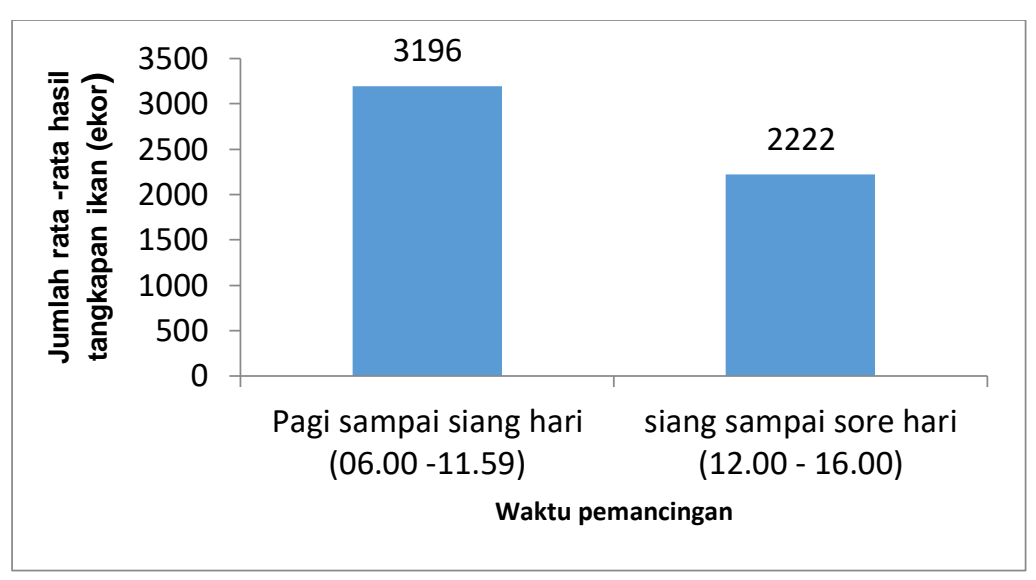

Gambar 3. Perbandingan rata - rata jumlah hasil tangkapan / trip pole and line antara waktu pagi sampai siang hari dan siang sampai sore hari

Perbandingan jumlah hasil tangkapan sebesar 3196 ekor dengan rata-rata setiap yang di kategorikan antara penangkapan pada waktu pagi sampai siang hari $(06.00-11.59)$ tripnya sebesar 106 ekor, sedangkan jumlah dan siang sampai sore hari $(12.00-16.00)$ total hasil tangkapan pada waktu siang sampai dengan rata - rata jumlah (ekor) hasil tangkapan berdasarkan trip yang dilakukan yaitu 30 sore hari sebesar 2222 ekor dengan rata - rata setiap tripnya sebesar 47 ekor.

Fluktuasi total hasil tangkapan berdasartrip. Dimana jumlah total hasil tangkapan yang di peroleh pada waktu pagi sampai siang hari kan jarak penangkapan dapat di lihat pada (Gambar 4).

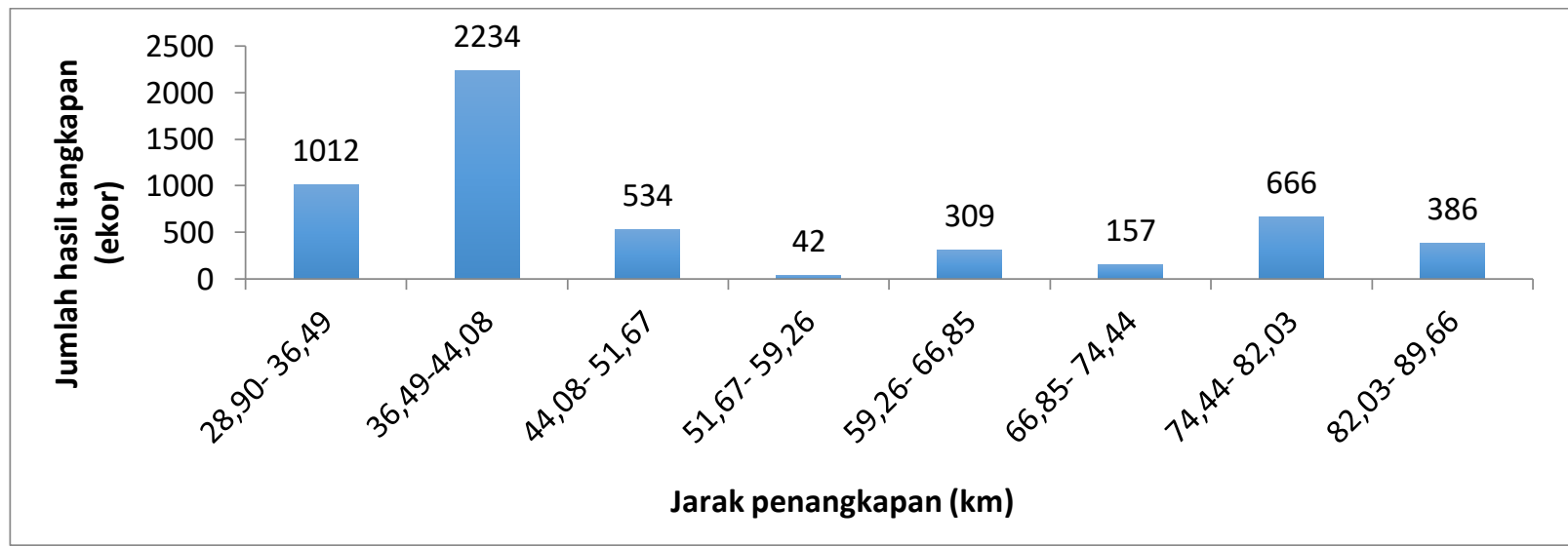

Gambar 4. Fluktuasi total hasil tangkapan berdasarkan jarak penangkapan

Gambar fluktuasi hasil tangkapan berdasarkan jarak penangkapan. Hasil tangkapan tertinggi berada pada interval jarak 36,49-44,08 dengan total hasil tangkapan 2234 ekor. Sedangkan terendah berada pada interval jarak 51,67 - 59,26 dengan total hasil tangkapan 42 ekor, interval jarak 36,49-44,08 memiliki jumlah hasil tangkapan terbesar dikarenakan interval jarak dengan angka ini terdapat dalam trip dan titik pemancingan dengan jumlah yang terbanyak dibandingkan dengan interval jarak yang lain, yang dengan demikian pula berarti bahwa 
interval jarak ini merupakan yang paling sering dikunjungi.

\section{Sebaran Daerah Penangkapan Ikan Pole and Line di Perairan Teluk Bone}

Daerah penangkapan pole and line di perairan Teluk bone, di Desa Murante,
Kecamatan Suli, Kabupaten Luwu,Sulawesi Selatan selama 30 trip penangkapan dapat di lihat pada (Gambar 5).

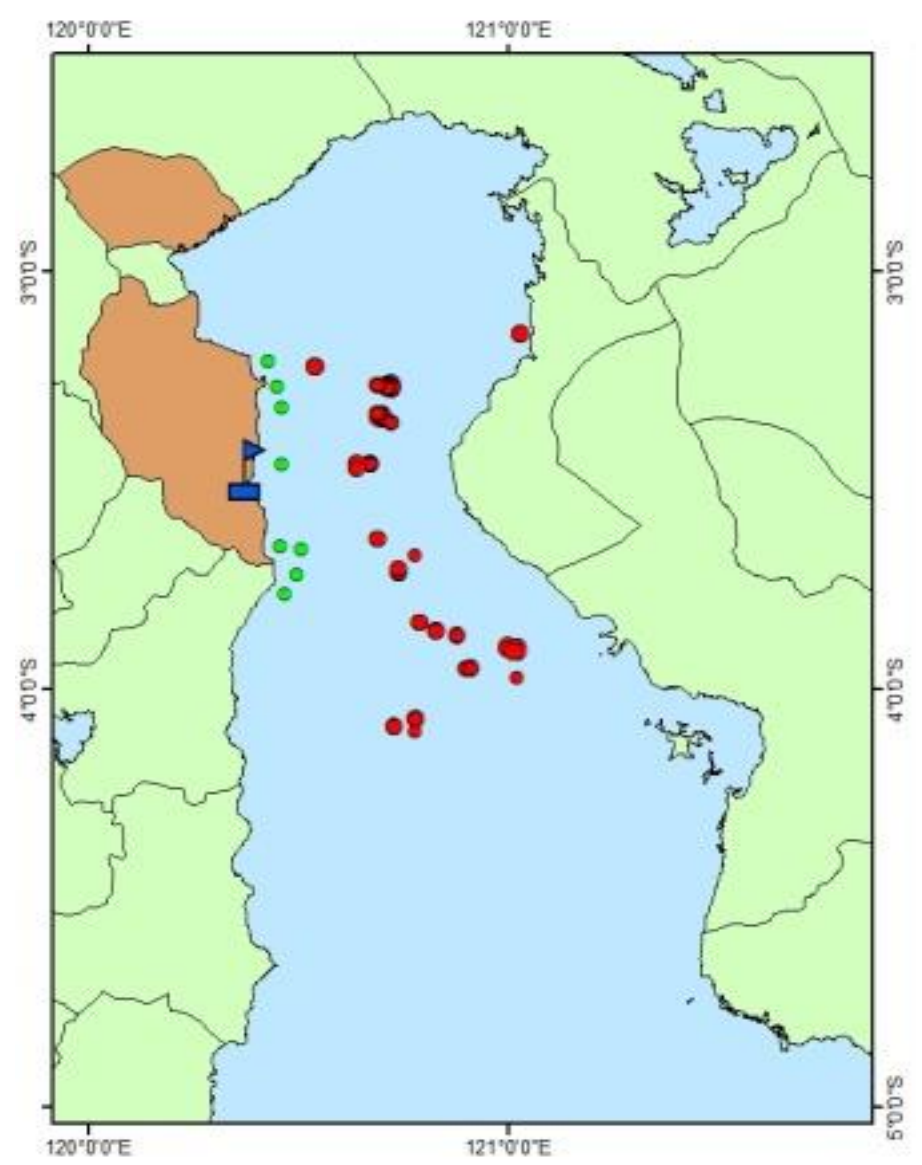

Gambar 5. Peta sebaran daerah penangkapan ikan pole and line di perairan Teluk Bone

Sebaran daerah penangkapan ikan pole and line di perairan Teluk Bone terlihat tersebar di bagian tengah perairan Teluk Bone, umumnya terkonsentrasi pada Teluk Bone bagian tengah. Titik tangkapan tertinggi berada lintang $03^{\circ} 16^{\prime} 29.2^{\prime \prime}$ bujur $120^{\circ} 43^{\prime}$ 00.5" dengan hasil tangkapan 114 ekor, dengan lama waktu pemancingan 13,13 menit pada pagi hari, jarak penangkapan 46,81 km, pada trip ke satu. Sedangkan titik tangkapan terendah berada pada lintang $04^{\circ} 06^{\prime} 01.5^{\prime \prime}$ bujur $120^{\circ} 46^{\prime} 54.9^{\prime \prime}$ dengan hasil tangkapan 2 ekor, lama waktu pemancingan 02.08 menit pada siang, jarak penangkapan 79,58 km, pada trip ke enam.

Jarak tempuh terjauh dari fishing base menuju fishing ground berada pada titik $03^{\circ} 58^{\prime} 11.4^{\prime \prime}$ bujur $121^{\circ} 01^{\prime} 27.0^{\prime \prime}$ 
dengan jarak 89,66 kilometer atau 48,42 mill laut dan jarak tempuh terdekat dari fishing base menuju fishing ground berada pada titik $03^{0} 27.913^{\prime}$ bujur $120^{\circ} 38.189^{\prime}$ dengan jarak 28,90 kilometer atau 15.60 mill laut.

Adapun sebaran pengambilan umpan dari alat tangkap bagan rambo terlihat pada titik yang warna hijau tersebar di sepanjang perairan pesisir dan ada tersebar di bagian barat Teluk Bone.

\section{KESIMPULAN}

1. Faktor teknis penangkapan yang berpengaruh terhadap jumlah hasil tangkapan di perairan Teluk Bone yang paling berpengaruh adalah lama waktu efektif pemancingan.

2. Sebaran daerah penangkapan ikan pole and line pada musim Timur di Perairan Teluk Bone berada terlihat tersebar di bagian tengah perairan Teluk Bone, umumnya terkonsentrasi pada Teluk Bone bagian tengah.

\section{DAFTAR PUSTAKA}

Ahmad Eden Ishal, 2012. Studi Perbandingan Jumlah Hasil Tangkapan Pole and Line (Huhate) Berdasarkan Waktu Penangkapan di Perairan Baubau. Program Studi Pemanfaatan Sumberdaya Perikanan. Jurusan Perikanan. Faukltas Ilmu Kelautan dan Perikanan Universitas Hasanuddin. Makassar.
Allen, Gerry. 1999. Marine Fishes of SouthEast Asia. Australia: Periplus Edition (HK). Ltd.

Fauzan. 2011. Pemetaan Daerah Potensial Penangkapan Ikan Cakalang Berbasis Sistem Informasi Geografi di Teluk Tomini. Program Studi Pemanfaatan Sumberdaya Perikanan. Jurusan Perikanan. Fakultas Ilmu Kelautan dan Perikanan Universitas Hasanuddin. Makassar.

Jumardi, 2011. Perbandingan Jumlah Hasil Tangkapan Pole and Line Berdasarkan Waktu Pemancingan. Di akses melalui http://noveladdie.blogspot.com/2011/0 3/tugas-akhir-pebandingan-jumlahhasil.html. Tanggal 29 oktober 2018.

Syahrir, S. 2012. Daerah Potensial Penangkapan Ikan Cakalang (Katsuwonus pelamis) Daerah Pole and Line Berdasarkan Produktivitas Penangkapan di Perairan TelukBone Kabupaten Luwu. Skripsi. Departemen dan Perikanan. Universitas Hasanuddin. Makassar. 